\title{
Different Approximation Levels in Using CFD for the Design of Hypersonic Vehicles
}

\author{
Antonio Schettino ${ }^{* 1}$ and Domenic D’Ambrosio ${ }^{2}$ \\ ${ }^{I}$ CIRA Italian Aerospace Research Centre, Capua (CE), 81043, Italy \\ ${ }^{2}$ Politecnico di Torino, Dipartimento di Ingegneria Meccanica e Aerospaziale, Torino, 10129, Italy
}

\begin{abstract}
In this paper the importance of using accurate CFD simulations in the design of hypersonic vehicles is stressed. The attention is focused on the one hand on the need to providing the vehicle designer with the estimated error bars together with the nominal values of the design parameters. On the other hand it is underlined how, in the different design phases, different levels of accuracy can be used, from simple inviscid computations to complex viscous non-equilibrium modellization, depending on the problem that must be solved. Then, the attention is focused on the kinetic models, from the classic macroscopic to the advanced models based on the state-to-state approach. Some examples of test cases that were used in the last years to validate CFD codes with respect to the kinetic modeling are presented, with the aim of emphasizing the potential advantages in using the state-to-state approach. Finally, preliminary results of the numerical rebuilding of wind tunnel test cases that are currently being performed in the framework of the Phys4Entry Project for code validation are shown.
\end{abstract}

Keywords: CFD, hypersonics, kinetic models, state-to-state models.

\section{INTRODUCTION}

In the last decades Computational Fluid Dynamics has acquired an important role in hypersonics, not only for research activities, but also as a practical design tool [1-3]. Depending on the design phase, CFD codes are used with different levels of accuracy. The present paper reports a synthesis of important CFD issues for the design of aerospace vehicles, mainly based on the direct experience of the authors.

During phase A, where several design loops are necessary to define the aerodynamic configuration, fast estimates are typically performed by means of engineering tools and inviscid or simplified CFD computations. During phase $\mathrm{B}$, aerodynamic and aerothermodynamic databases are determined by means of more complex CFD computations that take into account viscous and non-equilibrium effects. In this phase, available experiments are generally numerically rebuilt in order to validate the CFD results in representative conditions. Finally, during phase $\mathrm{C}$, detailed computations are normally repeated on the final configuration by using the best available physical modeling, in order to provide the final database, and local effects are numerically studied in detail.

The data that are typically needed in the design of a hypersonic vehicle can be classified in two main categories (Fig. 1):

*Address correspondence to this author at the CIRA Italian Aerospace Research Centre, Capua (CE), 81043, Italy; Tel: +39-0823-623327;

Fax: +39-0823-623700; E-mail: a.schettino@cira.it
- the aerodynamic database that includes all the aerodynamic coefficients (i.e. lift, drag, moments) as well as the derivatives of these coefficients with respect to a number of parameters (the so-called stability derivatives); the aerodynamic database is a fundamental input for flight mechanics in order to determine and optimize the vehicle trajectory and verify and guarantee its stability; furthermore, it provides mechanical loads for the sizing of the vehicle structure;

- the aerothermodynamic database that mainly includes the wall heat fluxes, that are necessary to size the Thermal Protection System (TPS), especially for reentry vehicles.

It must be stressed that for both aerodynamic and aerothermodynamic databases, in order to make the data practically useful for design purposes, the CFD specialist must provide not only the nominal values, but also the estimated error bar of each data. This is a fundamental aspect that is often not sufficiently taken into account and that sometimes makes it difficult to use CFD data for the sizing.

This topic is extensively discussed in [4], where the aerodynamic design of the USV vehicle is presented. In that paper, the different sources of error and their effects on aerodynamic and aerothermodynamic databases are dealt with.

A similar logic has been applied to the design of the Expert capsule also, as described in [5], where the nominal mechanical and heat loads and the related error bars are determined by means of CFD computations and experimental data. Furthermore, as far as the error bars are 


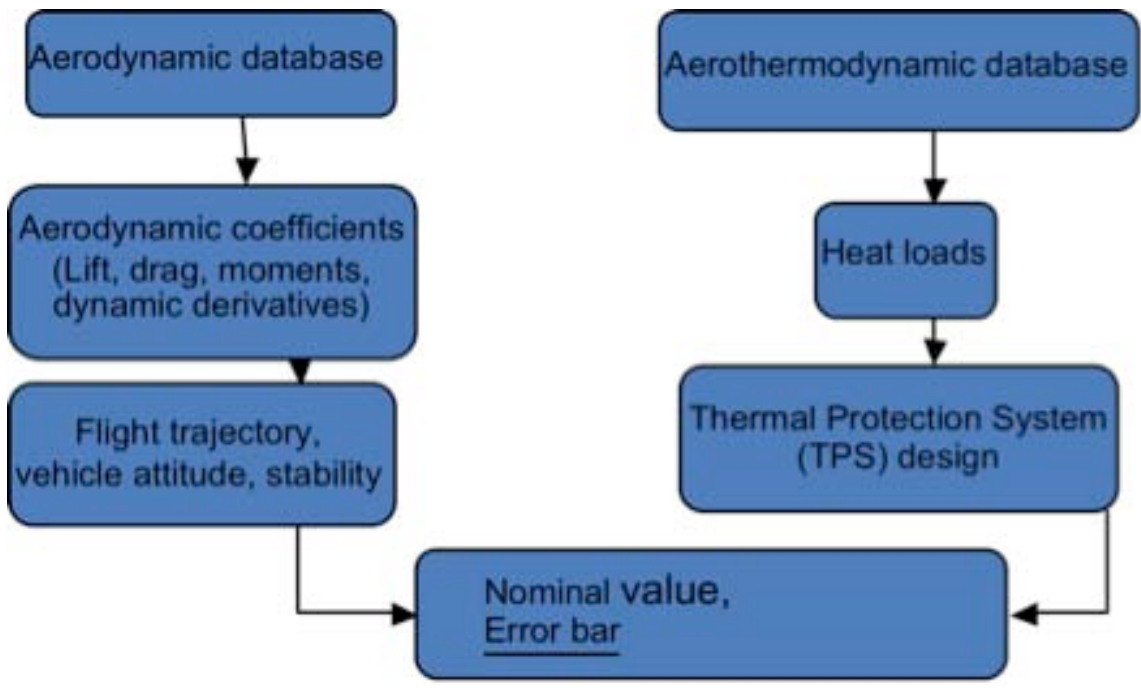

Fig. (1). Main parameters needed in the design of a hypersonic vehicle.

concerned, a clear distinction is made between tolerances and variations, that were defined as follows:

- Tolerances: The error in the determination of the nominal values, due to the approximation of both numerical and experimental methods and modeling;

- Variations: The error due to the fact that the "real flight" conditions are different from the ones used for the computations and for the experimental tests.

Tolerances are normally defined by the aerodynamic specialist, while variations are added by the designer. The aerodynamic coefficients are finally provided as a combination of nominal values, tolerances and variations.

$C_{i}=C_{i}^{N o m} \pm \Delta C_{i}^{T o l} \pm \Delta C_{i}^{\text {Var }}$

An example of the output is shown in Fig. (2) [5], where the pitching moment coefficient of the Expert capsule is shown. The error bars relevant to the tolerances are emphasized, together with the nominal values. In this case, the error bars are based on the one hand on the comparison with available experimental data in representative conditions, and on the other hand on the previous experience made validating the code in similar conditions. The numerical data were computed by means of different codes by several contributors. All the used codes have similar features, since they use a finite volume approach, different upwind numerical schemes and classic macroscopic kinetic models. When applicable (i.e. for high altitude cases), the KangDunn kinetic model was used in these simulations.

More recently, CFD was extensively used, along with ground experiments, for the definition of the aerodynamic and aerothermodynamic databases of the ESA Intermediate Experimental Vehicle IXV [6].

In order to estimate tolerances, several methods can be used. The accuracy of the final results normally depends on the numerical and on the physical modeling. As far as the numerical modeling is concerned, the CFD specialist should carefully verify not only the time convergence (in case of steady-state simulations), but also the grid convergence, by comparing the results obtained on different grids with increasing number of cells. The grid level that is needed obviously depends on the target parameters, but also on the design phase. In phase A, for example, coarser grids can be used to perform several fast computations and get the aerodynamic coefficients that mainly depend on the wall pressure. However, at least some computations must be performed using fine grids in order to estimate the error and provide the corresponding error bar to the designer. Starting from phase B, grid convergence should be always guaranteed by comparing the most significant and sensitive parameters, like the wall heat flux, on different grid levels.

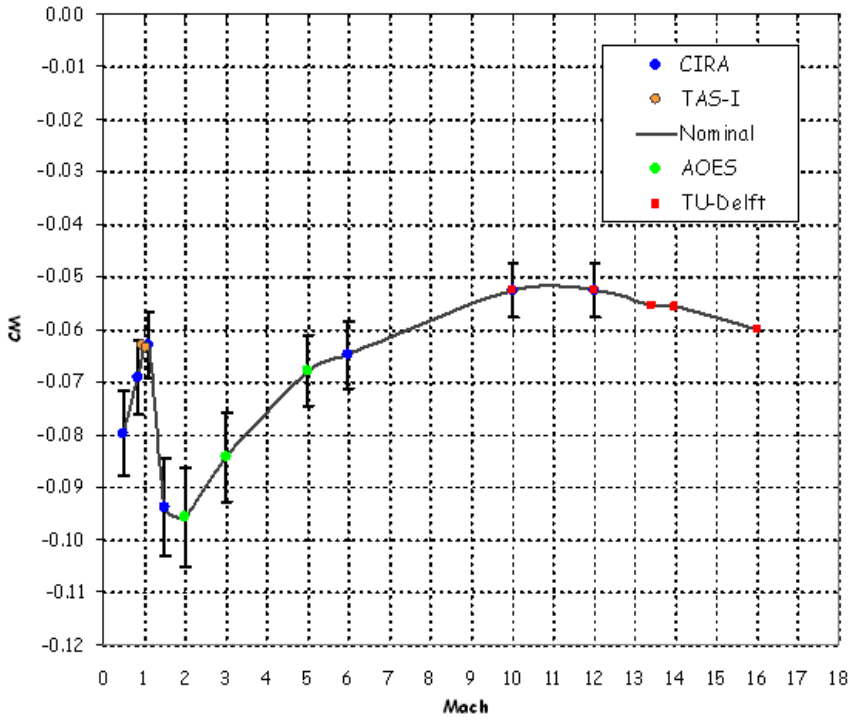

Fig. (2). Estimated moment coefficient of the Expert capsule as a function of Mach number [5].

The numerical scheme has normally an effect on the solution accuracy also, so that the most appropriate numerical scheme should be selected, depending on the target parameters.

However, the most critical aspect is often the physical modeling. Actually, both aerodynamic coefficients and the wall heat flux can be significantly influenced by the choice of the physical model, i.e. turbulence and thermochemical models. To properly define the error bar, on the one hand 
previous experiences made on similar problems can be used, and on the other hand it is important to perform and numerically rebuild representative experimental tests to validate numerical codes in similar conditions.

In some cases, very accurate physical models are available in principle, but they are not used because they are computationally too expensive. In these cases, the most accurate models can be used at least to estimate the tolerances.

As far as the kinetic model is concerned, for example, different levels can be considered; in phase A, preliminary computations can be performed assuming chemical equilibrium, which does not increase significantly the computation time and can be suitable to provide the aerodynamic coefficients. Nevertheless, non-equilibrium modellization is necessary to check the error due to such an approximation. Indeed, the error can be also significant, especially as far as the evaluation of the moment coefficient and of the flap efficiency are concerned. Macroscopic kinetic models are typically used (e.g. Park [7] or Kang-Dunn [8], for air), but very sophisticated state-to-state models can also be adopted for specific problems. In the following sections, some examples of applications of macroscopic and state-tostate kinetic models are shown, as well as some results recently obtained by using a novel macroscopic model, whose coefficients have been determined based on the stateto-state approach [11].

\section{KINETIC MODELS}

\section{A. Macroscopic Models}

Thermo-chemical non-equilibrium effects are included in CFD codes adding a number of new balance equations to the usual total mass, momentum and total energy conservation equations. The new balance equations account for changes in the mass of the chemical species and in the different contributions to the internal energy. The commonly used approach is the multi-temperature approach that assigns a different temperature to each degree of freedom in nonequilibrium within the gas and requires the integration of a relaxation equation for each temperature. Usually, in aerospace applications, the rotational energy is assumed to be in equilibrium with the translational energy. These two energies are described by the so-called roto-translational temperature. Conversely, the vibrational energy of multiatomic species is thought to be in non-equilibrium conditions and a balance equation for the vibrational energy of each multi-atomic species has to be solved. Once the vibrational energy at a given point and instant is known, it can be described by its vibrational temperature. If the gas energy is sufficiently high, species electronic energy can be assumed to be in non-equilibrium also. Therefore, an electronic temperature different from the roto-translational and the vibrational temperature may also be defined. When ionization processes are present, free-electrons may populate the flow field. The electrons translational energy is typically in non-equilibrium also, so that an electron temperature may be defined. Since the internal energy of atoms or molecules affects the chemical reaction rates, the latter should be considered as functions of the various temperatures that are defined within the used model. The complexity of a thermochemical non-equilibrium model depends to what extent the effect of internal energy non-equilibrium is accounted for in the evaluation of chemical reaction rates, and vice-versa.

Using macroscopic models, one assumes that the internal energy of molecules is distributed across the energy levels according to the Boltzmann distribution, even in thermodynamic non-equilibrium conditions. Thus, a single local value of the internal energy is associated to each molecular species. For example, we consider the rotational, vibrational and electronic specific energies of molecular oxygen as single local values, namely $e^{r} \mathrm{O}_{2}(x, t), e^{v}{ }_{\mathrm{O} 2}(x, t)$, $e^{e}{ }^{e}(x, t)$, without taking into account how these energies are distributed. The distribution is assumed a priori and this is why it is possible to define a temperature that pertains to a given energy of a given species. Using macroscopic models, we are interested in calculating the evolution of the concentrations of each molecular species, for example the mass fraction $y_{\mathrm{O} 2}$, but not the evolution of the populations of the energy levels. We will also need a model to evaluate the evolution of the internal energies of the single species.

The additional balance equations that are added to the classical governing equations of fluid dynamics are:

$$
\begin{aligned}
& \frac{\partial \rho_{i}}{\partial t}+\nabla \cdot\left(\rho_{i} v\right)+\nabla \cdot J_{m_{i}}=\Omega_{i}^{c h} \quad i=1, N_{s} \\
& \frac{\partial \rho e_{j}^{v}}{\partial t}+\nabla \cdot\left(\rho e_{j}^{v} v\right)+\nabla \cdot J_{e_{j}^{v}}=\Omega_{j}^{v} \quad j=1, N_{v}
\end{aligned}
$$

In the equations above, the attention was restricted to chemical and vibrational non-equilibrium. Eq. (1) is the mass balance equation for a generic $i$-th chemical species and Eq. (2) is the vibrational energy balance equation for a generic $j$-th species. At the left-hand side, time change, convection and diffusion can be recognized, while the source terms at right-hand side contain the chemical rates and the vibrational energy rates, respectively. As an example, the number of additional equations for a gas mixture composed of $\mathrm{O}_{2}, \mathrm{~N}_{2}, \mathrm{NO}, \mathrm{O}$ and $\mathrm{N}$ (air without ionization) is eight: Five species mass balance equations and three vibrational energy balance equations (assuming the vibrational energy of $\mathrm{O}_{2}$, $\mathrm{N}_{2}$, NO are in non-equilibrium conditions).

\section{B. State-to-State Models}

State-to-state models consist in solving the balance equation for all the internal states of the degree of freedom (usually vibration) that is not in equilibrium. Using state-tostate models, the energy distributions are not assumed and the evolution of the population of the different energy levels must be computed. For example, the global specific vibrational energy of molecular oxygen will be obtained as the sum of the vibrational energies of each level:

$e_{O_{2}}^{v}=\sum_{\ell=1}^{N_{O_{2}}^{v, \ell}} y_{O_{2}, \ell}^{v} e_{O_{2}, \ell}^{v}$

where $y_{O 2, \ell}^{v}$ is the mass fraction of $\mathrm{O}_{2}$ that populates the $\ell$-th vibrational energy level and $e^{v}{ }_{2}, \ell$ is the specific energy of the $\ell$-th vibrational energy level, which is a given quantity. Here, we are interested in calculating the evolution of the populations of the energy levels, $y_{O 2, \ell}^{v}$. 
The internal (vibrational) temperatures obtained by stateto-state calculations and related to the first energy levels reproduce the results obtained by macroscopic models. On the other hand, the chemical rate coefficients, which in the state-to-state approach are calculated as the mean value of the state-to-state rates weighted over the internal distribution, are very different. In multi-temperature models, the rate coefficients are calculated following the Arrhenius trend with a temperature that is the weighted geometrical mean of the temperatures involved in the process (Park model), or using coupling functions that also depend on the involved temperatures (CVD models). In the state-to state approach, rates are influenced by the vibrational distributions; in case of strong departures from the Boltzmann distribution, with strongly overpopulated tails, the rate coefficients do not follow the Arrhenius law, showing in some cases an opposite trend. The most difficult problem in state-to-state modeling is the lack of kinetic data (rates for selected states). To complete the data set, the ladder climbing model is often used that estimates the chemical rates from available data.

When a state-to-state approach is used to model thermochemical non-equilibrium, the additional balance equations that are added to the classical governing equations of fluid dynamics are:

$$
\frac{\partial \rho_{i, \ell}}{\partial t}+\nabla \cdot\left(\rho_{i, \ell} \nu\right)+\nabla \cdot J_{m_{i, \ell}}=\Omega_{i, \ell}^{c h} \quad i=1, N_{s}, \quad \ell=1, N_{i}^{v, \ell}
$$

where $\ell$ is a generic vibrational level of the $i$-th species. Thus, vibrational energy balance equations are not needed if a state-to-state chemistry approach is adopted, but the number of species mass balance equations dramatically increases. For example, the typical number of vibrational energy levels of $\mathrm{O}_{2}$ is 34 .

Note that, when we adopt a state-to-state approach to simulate thermo-chemical non-equilibrium, we have to model the production term, $\Omega_{i,}^{v} \ell$ and the diffusive flux, $\mathrm{J}_{\mathrm{mi}}, \ell$. The latter can be assumed to be the same for each energy level of a given species, while the former depends on the particular energy level and on the processes that influence that energy level. Thus, the chemical reactions scheme for state-to-state models is much more complex than for macroscopic models. To show the difference, in Table $\mathbf{1}$ we compare the reaction schemes for a gas mixture composed of

Table 1. List of chemical processes to be considered using macroscopic (up) and a state-to-state (down) models.

\begin{tabular}{|l|l|}
\hline \multicolumn{1}{|c|}{$\mathbf{r}$} & \multicolumn{1}{|c|}{ Reaction } \\
\hline \hline 1 & $\mathrm{O}_{2}+\mathrm{O} \leftrightharpoons 2 \mathrm{O}+\mathrm{O}$ \\
2 & $\mathrm{O}_{2}+\mathrm{N} \leftrightharpoons 2 \mathrm{O}+\mathrm{N}$ \\
3 & $\mathrm{O}_{2}+\mathrm{NO} \leftrightharpoons 2 \mathrm{O}+\mathrm{NO}$ \\
4 & $\mathrm{O}_{2}+\mathrm{O}_{2} \leftrightharpoons 2 \mathrm{O}+\mathrm{O}_{2}$ \\
5 & $\mathrm{O}_{2}+\mathrm{N}_{2} \leftrightharpoons 2 \mathrm{O}+\mathrm{N}_{2}$ \\
6 & $\mathrm{~N}_{2}+\mathrm{O} \leftrightharpoons 2 \mathrm{~N}+\mathrm{O}$ \\
7 & $\mathrm{~N}_{2}+\mathrm{N} \leftrightharpoons 2 \mathrm{~N}+\mathrm{N}$ \\
8 & $\mathrm{~N}_{2}+\mathrm{NO} \leftrightharpoons 2 \mathrm{~N}+\mathrm{NO}$ \\
9 & $\mathrm{~N}_{2}+\mathrm{O}_{2} \leftrightharpoons 2 \mathrm{~N}+\mathrm{O}_{2}$ \\
10 & $\mathrm{~N}_{2}+\mathrm{N}_{2} \leftrightharpoons 2 \mathrm{~N}+\mathrm{N}_{2}$ \\
11 & $\mathrm{NO}+\mathrm{O} \leftrightharpoons 2 \mathrm{O}+\mathrm{N}$ \\
12 & $\mathrm{NO}+\mathrm{N} \leftrightharpoons 2 \mathrm{~N}+\mathrm{O}$ \\
13 & $\mathrm{NO}+\mathrm{NO} \leftrightharpoons \mathrm{N}+\mathrm{O}+\mathrm{NO}$ \\
14 & $\mathrm{NO}+\mathrm{O}_{2} \leftrightharpoons \mathrm{N}+\mathrm{O}+\mathrm{O}_{2}$ \\
15 & $\mathrm{NO}+\mathrm{N}_{2} \leftrightharpoons \mathrm{N}+\mathrm{O}+\mathrm{N}_{2}$ \\
16 & $\mathrm{NO}+\mathrm{O} \leftrightharpoons \mathrm{N}+\mathrm{O}_{2}$ \\
17 & $\mathrm{~N}_{2}+\mathrm{O} \leftrightharpoons \mathrm{N}+\mathrm{NO}$ \\
\hline
\end{tabular}

\begin{tabular}{|c|c|c|c|}
\hline 1 & $\mathrm{~N}_{2}(M)+\mathrm{N}_{2} \leftrightharpoons 2 \mathrm{~N}+\mathrm{N}_{2}$ & 14 & $\mathrm{~N}_{2}(v)+\mathrm{O}_{2} \leftrightharpoons 2 \mathrm{~N}+\mathrm{O}_{2}$ \\
\hline 2 & $\mathrm{~N}_{2}(v)+\mathrm{N}_{2} \leftrightharpoons \mathrm{N}_{2}(v-1)+\mathrm{N}_{2}$ & 15 & $\mathrm{~N}_{2}(v)+0 \leftrightharpoons \mathrm{N}_{2}(v-1)+0$ \\
\hline 3 & $\mathrm{~N}_{2}(v)+\mathrm{N}_{2}(M) \leftrightharpoons \mathrm{N}_{2}(v-1)+2 \mathrm{~N}$ & 16 & $\mathrm{~N}_{2}(v)+0 \leftrightharpoons 2 \mathrm{~N}+\mathrm{O}$ \\
\hline 4 & $\mathrm{~N}_{2}(v)+\mathrm{N}_{2}(w-1) \leftrightharpoons \mathrm{N}_{2}(v-1)+\mathrm{N}_{2}(w)$ & 17 & $\mathrm{O}_{2}(v)+\mathrm{N}_{2} \leftrightharpoons \mathrm{O}_{2}(v-1)+\mathrm{N}_{2}$ \\
\hline 5 & $\mathrm{~N}_{2}(v)+\mathrm{N} \leftrightharpoons 2 \mathrm{~N}+\mathrm{N}$ & 18 & $\mathrm{O}_{2}(v)+\mathrm{N}_{2} \leftrightharpoons 2 \mathrm{O}+\mathrm{N}_{2}$ \\
\hline 8 & $\mathrm{O}_{2}(v)+\mathrm{O}_{2}(M) \leftrightharpoons \mathrm{O}_{2}(v-1)+20$ & 21 & $\mathrm{O}_{2}(v)+\mathrm{N}_{2}(w-1) \leftrightharpoons \mathrm{O}_{2}(v-2)+\mathrm{N}_{2}(w)$ \\
\hline 9 & $\mathrm{O}_{2}(v)+\mathrm{O}_{2} \leftrightharpoons \mathrm{O}_{2}(v-1)+\mathrm{O}_{2}$ & 22 & $\mathrm{NO}(0)+0 \leftrightharpoons 20+\mathrm{N}$ \\
\hline 10 & $\mathrm{O}_{2}(M)+\mathrm{O}_{2} \leftrightharpoons 2 \mathrm{O}+\mathrm{O}_{2}$ & 23 & $\mathrm{NO}(0)+\mathrm{N} \leftrightharpoons \mathrm{O}+2 \mathrm{~N}$ \\
\hline 11 & $\mathrm{O}_{2}(v)+\mathrm{O} \leftrightharpoons \mathrm{O}_{2}(v-\mathrm{d} v)+\mathrm{O}$ & 24 & $\mathrm{NO}(0)+\mathrm{NO} \leftrightharpoons \mathrm{N}+\mathrm{O}+\mathrm{NO}$ \\
\hline 12 & $\mathrm{O}_{2}(v)+0 \leftrightharpoons 20+0$ & 25 & $\mathrm{NO}(0)+\mathrm{O}_{2} \leftrightharpoons \mathrm{N}+\mathrm{O}+\mathrm{O}_{2}$ \\
\hline
\end{tabular}


5 specie, namely $\mathrm{O}, \mathrm{N}, \mathrm{NO}, \mathrm{O}_{2}$ and $\mathrm{N}_{2}$. Only vibrational nonequilibrium processes are accounted for.

In the state-to-state model we have a list of 26 processes, but note that when ' $\mathrm{v}$ ' or ' $\mathrm{w}$ ' is indicated next to a diatomic species, it varies from 1 to the number of energy levels of that species. Therefore, the total number of processes that are accounted for is definitely larger than 26. A large number of processes implies a large computational cost for each evaluation of non-equilibrium source terms.

\section{EXAMPLES OF TEST CASES SIMULATION}

In this section some examples of simulations performed by the authors in previous projects for code validation purposes are shown, with the goal of emphasizing the importance of designing and carrying out representative experiments for code validation.

The first two simulations that will be shown were used to check the code capability to provide reliable data in presence of flow separation. This is a typical problem of practical interest, because the flow separation phenomenon can significantly affect the flap efficiency of a hypersonic vehicle.

Afterwards, we will present some examples of the numerical rebuilding of experiments that were carried out inside a hypersonic nozzle. The strong expansion occurring in a nozzle is a typical case where the accuracy of the kinetic model is very important, especially when one is interested in an accurate estimate of the ionization level.

The results presented in subsection III.A have been obtained by using the Computational Fluid Dynamics (CFD) code H3NS developed at CIRA. The code solves full Reynolds Averaged Navier-Stokes (RANS) equations and considers the air flow in thermo-chemical non-equilibrium. Several macroscopic kinetic models are implemented in H3NS, including the well known Park model with five species $\left(\mathrm{O}, \mathrm{N}, \mathrm{NO}, \mathrm{O}_{2}, \mathrm{~N}_{2}\right)$ and 17 chemical reactions [7]. The energy exchange between vibrational and translational temperature is based on the Landau-Teller non-equilibrium equation, with average relaxation times taken from the Millikan-White [21] theory modified by Park. The viscosity coefficient for the single species is computed by means of Yun and Mason collision integrals [22], while for the conductivity coefficients Eucken's law is used. Diffusion coefficients are obtained again by Yun and Mason tabulated collision integrals [22].

From the numerical point of view, the code is based on a finite volume approach with a cell centered formulation. The inviscid fluxes are computed using a Flux Difference Splitting scheme [23] and second order accurate approximation is obtained with an Essentially Non Oscillatory (ENO) reconstruction of interface values. Time evolution is performed by an explicit multistage RungeKutta algorithm coupled with an implicit evaluation of the source terms.

Test cases presented in subsection III.B were computed using the CAST code. The latter was developed in the framework of a dedicated project funded by the Italian Space Agency and it represents an improvement of the H3NS code, including additional different models and in particular a novel macroscopic model based on the state-to-state approach.

Finally, in subsection C, we show some results that were obtained using a quasi-1D state-to-state code developed at the Politecnico di Torino and at CNR-IMIP, in order to emphasize the expected differences with respect to macroscopic models.

\section{A. Flow Separation Test Cases}

In [8] a double cone test case at Mach 9 was tested and numerically rebuilt. The activity was carried out in the framework of the CAST Project, funded by the Italian Space Agency (ASI) and devoted to the development of a numerical code able to simulate high-enthalpy reacting flows on complex geometries by means of state-of-the-art physical models.

Several experimental tests were performed in the HEAT facility at ALTA (Pisa, Italy) and numerical simulations for some representative conditions were carried out using two different numerical codes, developed by CIRA (H3NS) and by the "Politecnico" di Torino. Both CFD tools use a finite volume approach and the same upwind numerical scheme. The Park kinetic model was selected for this test case [7]. Details about the codes are described in [9].

In the code validation exercise, the attention was focused on the experiments corresponding to the freestream conditions listed in Table 2.

Table 2. Freestream conditions for the numerical rebuilding of the double-cone experiments [9].

\begin{tabular}{|c|c|c|}
\hline ID & $\mathbf{p}^{\mathbf{0}}[\mathbf{b a r}]$ & $\mathbf{h}^{\mathbf{0}}[\mathbf{M J} / \mathbf{k g}]$ \\
\hline \hline Run 8 (12-03-2008) & 3.11 & 3.61 \\
\hline Run 3 (13-03-2008) & 3.17 & 4.64 \\
\hline
\end{tabular}

In Fig. (3) the typical flow structure that is expected from the experiment is shown, while in Fig. (4) an example of the Mach number contour is plotted for one of the experimental conditions.

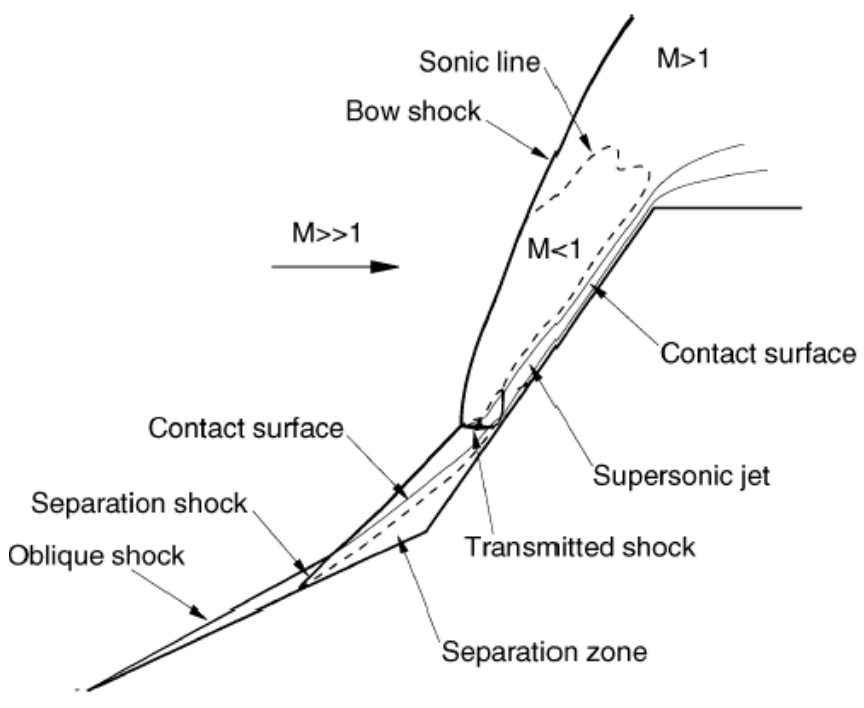

Fig. (3). Shock interaction pattern [10]. 


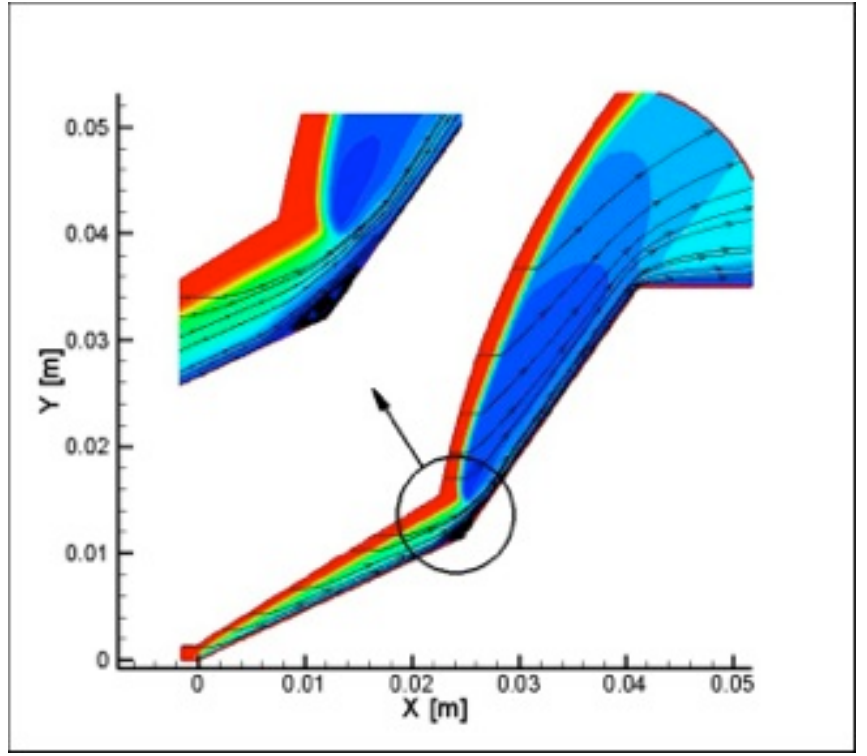

Fig. (4). Mach number contour (run 3) [9].

In Fig. (5) and Fig. (6), the comparison is shown between numerical and experimental results, in terms of wall heat flux and pressure.

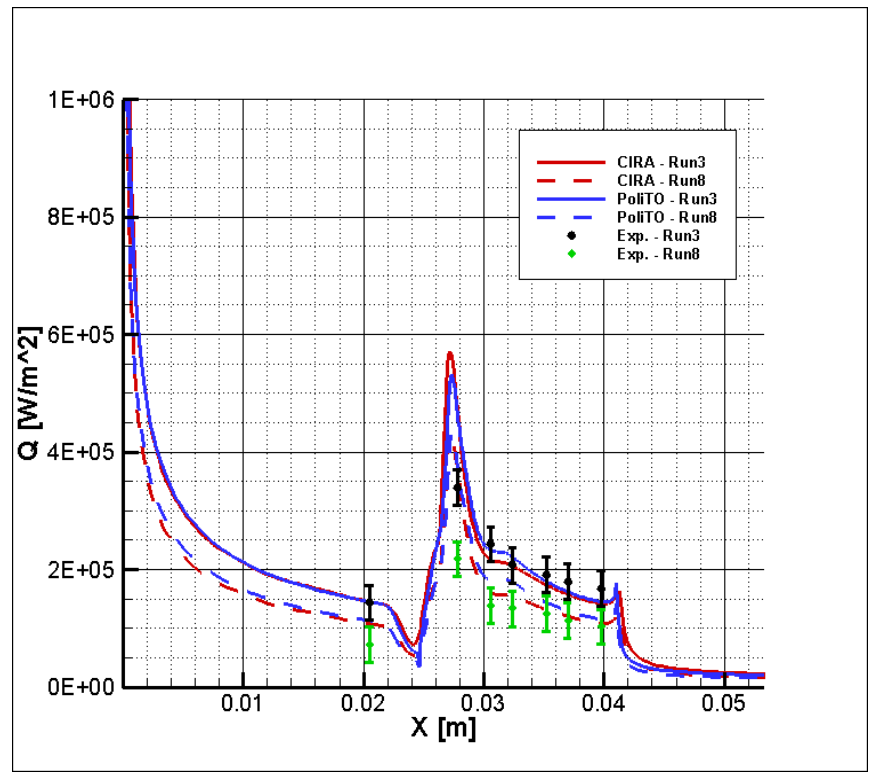

Fig. (5). Wall heat flux. Comparison between numerical results and experimental data [9].

It can be seen that, with respect to the experimental data, both CFD codes show a good agreement as far as the wall heat flux is concerned, while the comparison is less satisfactory for the wall pressure. A sensitivity analysis was performed also, by changing physical models (wall catalysis) and free-stream conditions, that were re-computed by simulating the entire nozzle flow. This last point came out to be the most relevant. Actually, in [9] it was shown how the correct modelling of the nozzle flow has a significant effect on the final solution over the double cone, and allows for a better agreement for wall pressure also. This fact can be seen in Fig. (6), where the green line represents the wall pressure recomputed with updated free-stream conditions obtained by means of an accurate simulation of the nozzle flow.

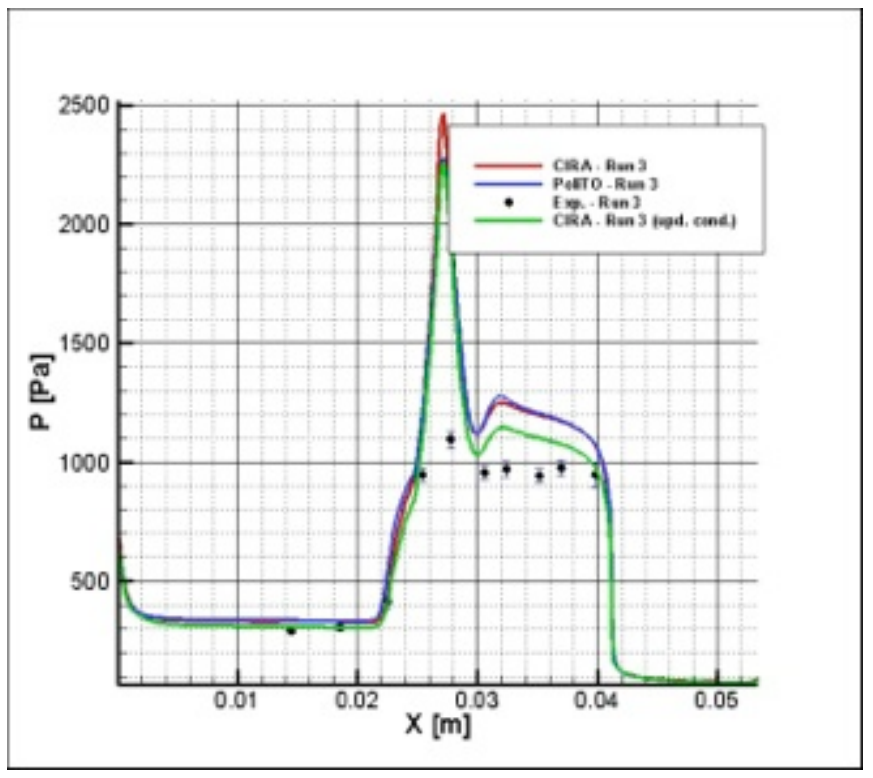

Fig. (6). Wall pressure. Comparison between numerical results and experimental data [9].

In [11] another experiment devoted to the study of shock wave - boundary layer interaction inducing flow separation is discussed. This experiment was carried out in the Scirocco Plasma Wind Tunnel at CIRA. A flap that represents one of those designed and built for the Expert capsule was mounted on a model holder. The goal of the test was to reproduce in a ground experiment freestream conditions close to real flight, in order to obtain a flow separation on the flap similar to the one foreseen in flight.

In [11], details about the numerical computations are given, while in [12] experimental results are shown, together with details on the related ESA Expert capsule flight experiment that was designed and set-up by CIRA.

With respect to the previously described double cone experiment, which is characterized by a total enthalpy of approximately $5 \mathrm{MJ} / \mathrm{kg}$, the energy level is significantly higher here (up to $15 \mathrm{MJ} / \mathrm{kg}$ ) and the model dimensions are much bigger, being the nose radius equal to $0.1 \mathrm{~m}$ and the model total length equal to $0.6 \mathrm{~m}$. Therefore, in this case, real gas effects are much stronger than in the double-cone experiment. As in the previous simulations, the Park [7] kinetic model was used here also.

In Fig. (7) the pressure contours over half model are shown, while in Fig. (8) one can see a detail of the flap region. Here, skin friction lines are also plotted, in order to emphasize the separation zone.

Several sensors were embedded in the test article to acquire useful data for code validation. Pressure transducers (PT) and thermocouples (TC) were installed on both the model holder and the flap. A very important measurement was performed by means of a combined pressure/heat flux sensor (CFP) specifically designed for the Expert capsule and qualified in the Scirocco wind tunnel. In Fig. (9), the positions of all the sensors are emphasized, while in Fig. (10) the comparison between numerical and experimental data is shown. It can be seen that a very good agreement was obtained in this case. 


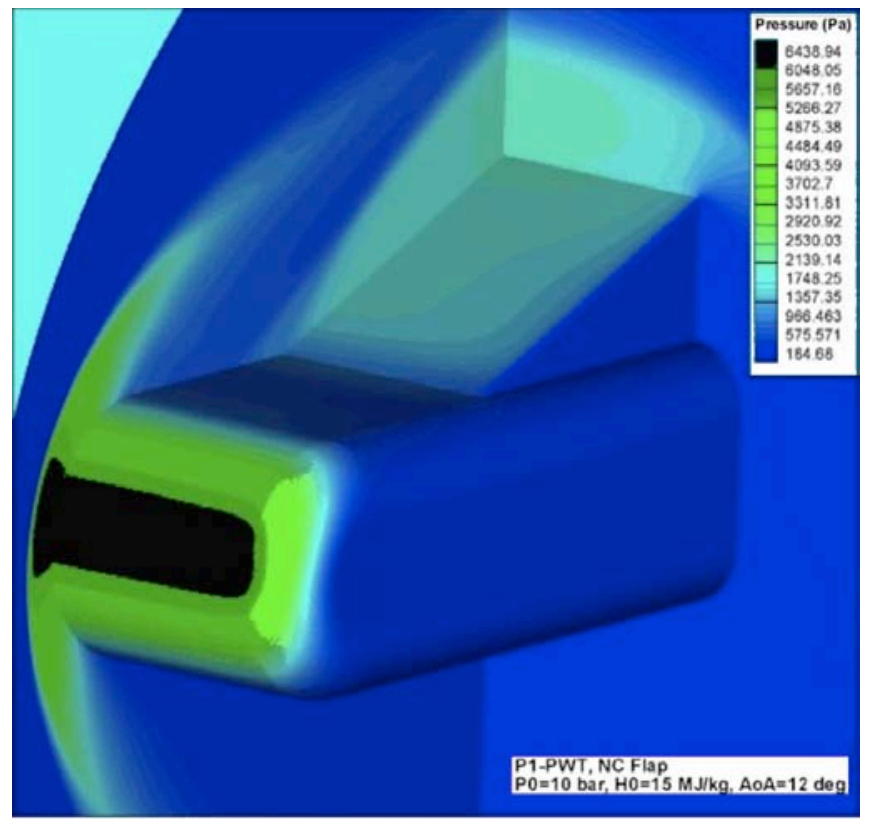

Fig. (7). CLAE model. Computed pressure contours [11] (model length $=0.6 \mathrm{~m})$.

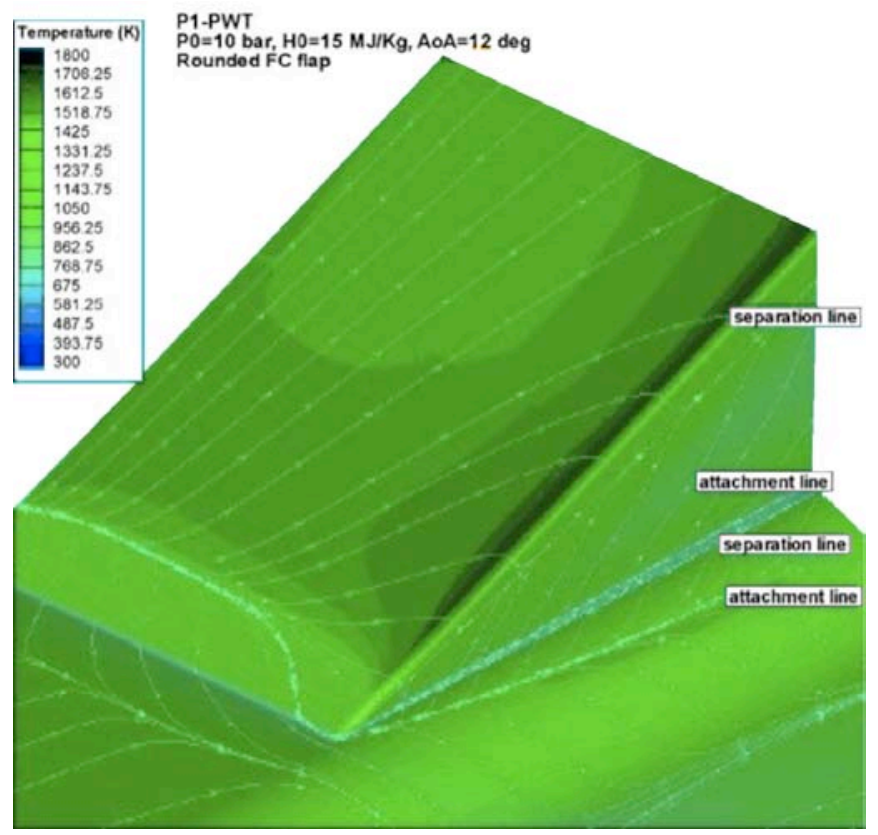

Fig. (8). CLAE model. Computed temperature contours over the flap and separation zone [11].

\section{B. Nozzle Test Cases}

The effect of the choice of a given chemical model is particularly important in hypersonic nozzle flows, where the expansion is strongly affected by chemical non-equilibrium conditions.

In the framework of the already cited CAST Project, a novel macroscopic model was proposed by CNR-IMIP at Bari, whose coefficients were determined by means of stateto-state computations. Such a model was used, together with the macroscopic Kang-Dunn model, to simulate the flow inside the Scirocco nozzle, whose geometry is shown in Fig. (11).

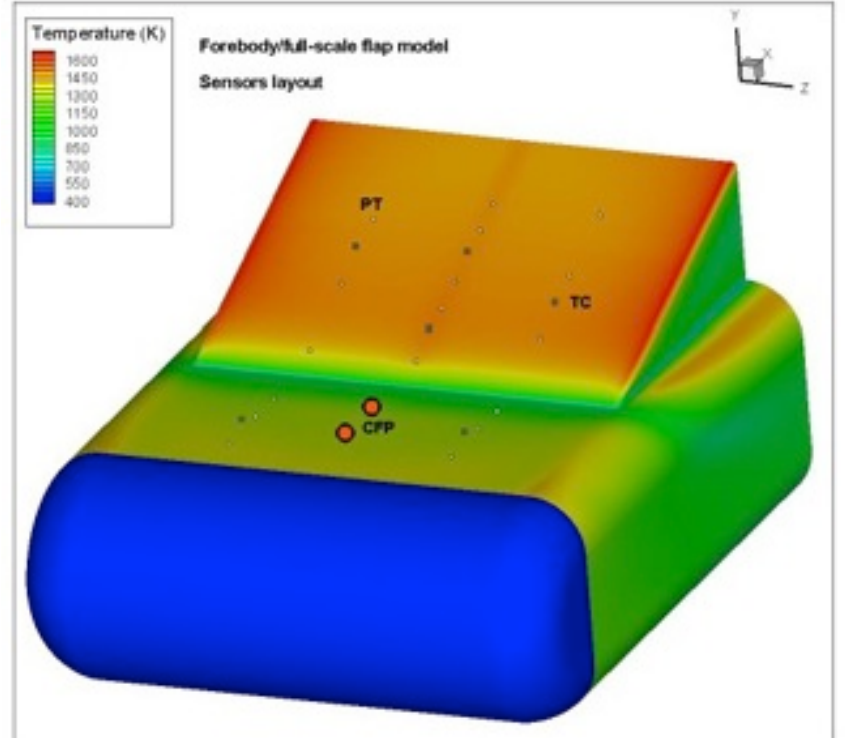

Fig. (9). CLAE model. Sensors location [11].

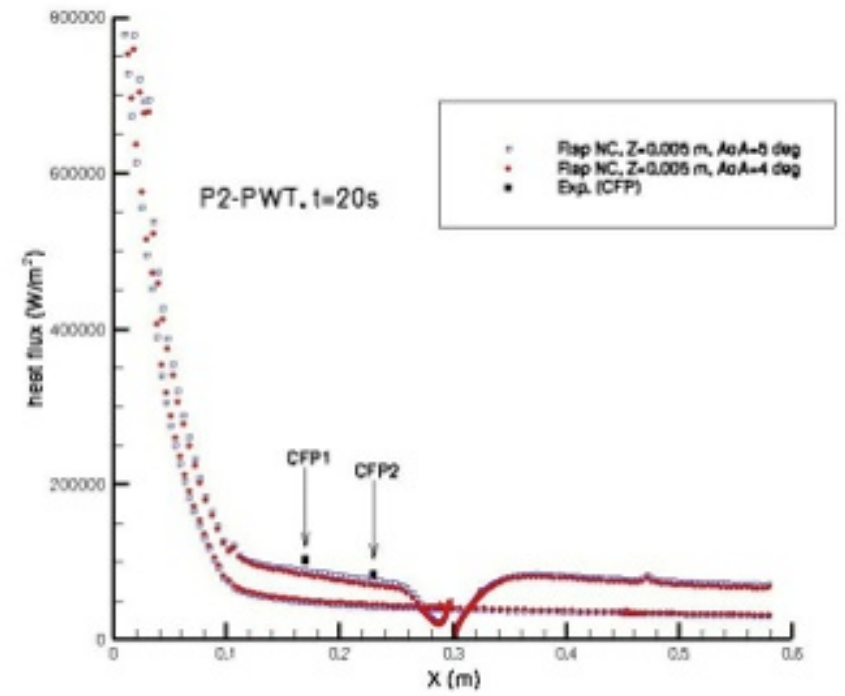

Fig. (10). CLAE model. Wall heat flux. Comparison between numerical and experimental results [12].

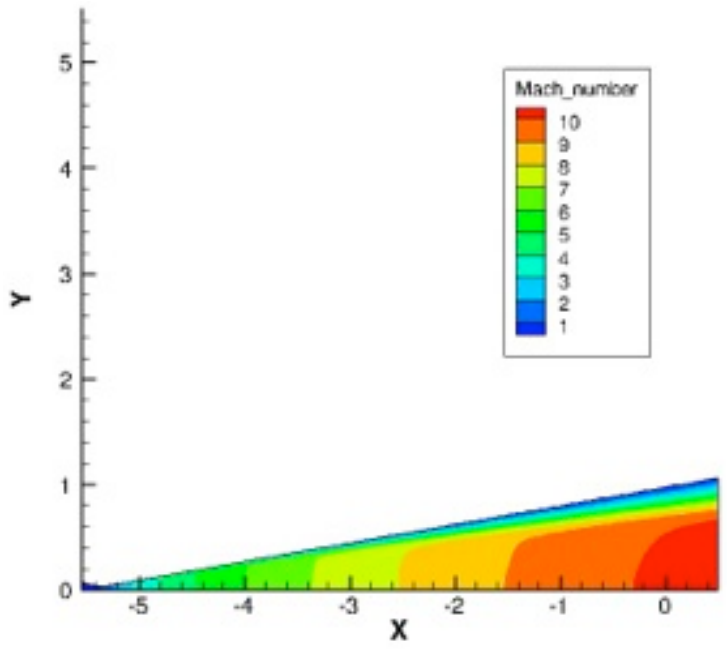

Fig. (11). Scirocco nozzle. Mach number contour [14]. 


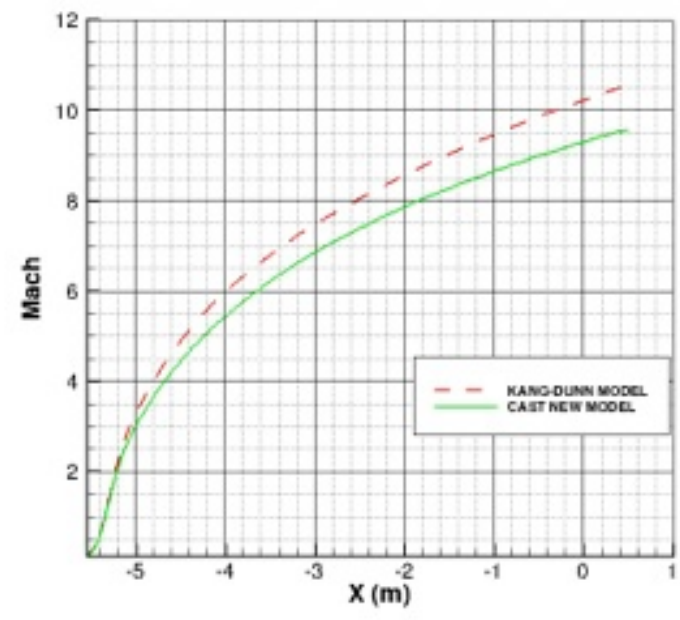

Fig. (12). Mach and temperature plots along the Scirocco nozzle axis [14].

It is worth underlining that very few data are available to validate CFD codes with respect to the electron number density $n_{e}$, though this parameter was particularly important within that project, since one of the goals was to study MHD interaction, that is strongly influenced by the freestream electron number density.

In Fig. (12), Mach number and temperature distributions along the nozzle axis obtained using the Kang-Dunn and the new CAST models are compared. It can be seen that the latter provides a less intense expansion with respect to KangDunn.

However, the most important result is shown in Fig. (13), where the computed electron number density, $n_{e}$, is plotted and compared with the experimental data measured at the nozzle exit. It can be seen that the new CAST model provides a higher value of $n_{e}$ with respect to Kang-Dunn, very close to the experimental one.

A similar promising result was obtained for the Scirocco nozzle also in a different test condition, characterized by a lower total enthalpy, and also in a smaller research facility, named GHIBLI, also available at CIRA [15], for which experimental results were produced again in the framework of the CAST Project.

\section{State-to-State Computations}

In this section we show an example of a state-to-state simulation in a hypersonic nozzle flow. Details about the used thermochemical models and numerical method can be found in [16]. The numerical prediction aims at reproducing one of the experiments conducted in the NASA Ames EAST facility nozzle by Sharma, et al. $[17,18]$. The working gas is pure nitrogen and the stagnation conditions for the considered experiment are defined in Table 3, which correspond to case B of reference [19]. For the sake of

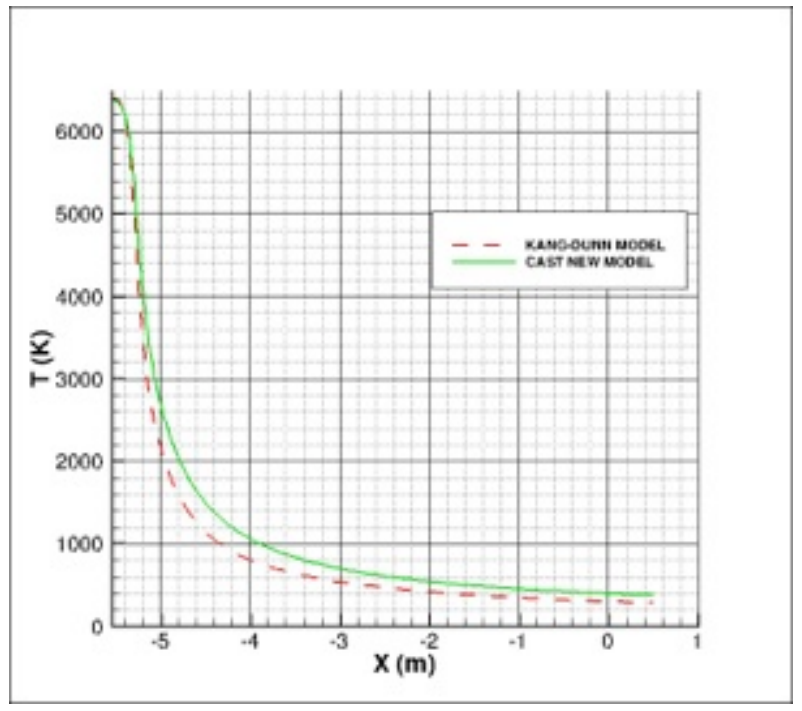

simplicity, quasi-one-dimensional simulations were carried out.

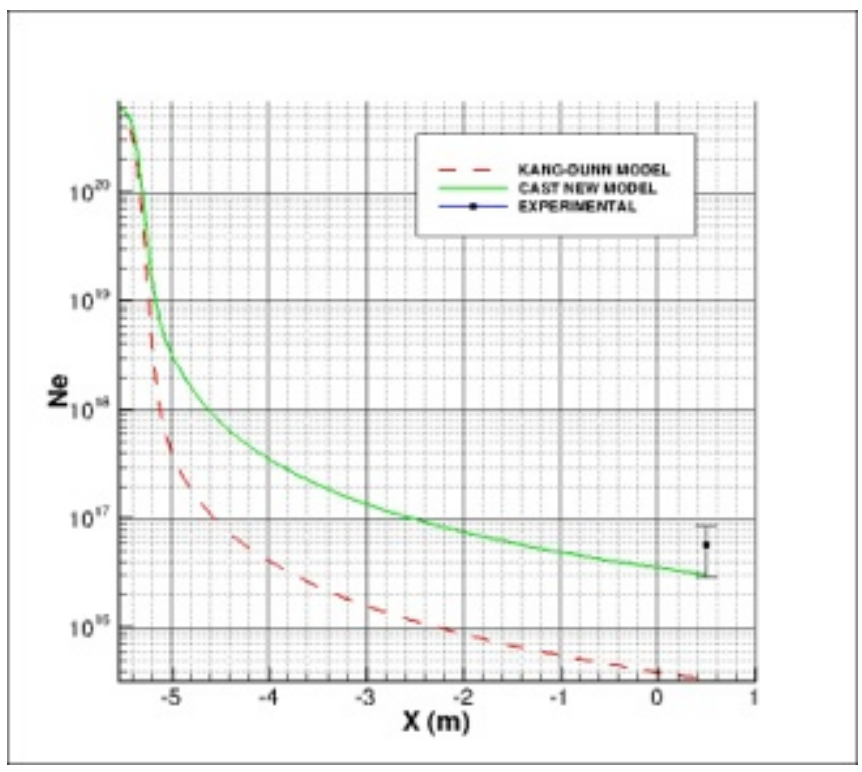

Fig. (13). Electron density along the axis of Scirocco nozzle; comparison between numerical results and experimental data [11].

As expected, the results of the state-to-state model are characterized by a strong freezing of the distributions tails to values larger than those predicted by the Boltzmann distribution (Fig. 14). The freezing starts before the throat and induces a slightly faster recombination, as shown in Fig. (15) (left). In this particular test case, the differences between the state-to-state and the macroscopic models are quite small. This can be partly due to the consistency that exists between the two models. The only significant difference is in the recombination of the atomic nitrogen $\mathrm{N}$,

Table 3. Stagnation conditions used in the simulation of the EAST nozzle experiments.

\begin{tabular}{|c|c|c|c|c|c|c|}
\hline Experiment & $\mathbf{h}^{\mathbf{0}}[\mathbf{M J} / \mathbf{k g}]$ & $\mathbf{p}^{\mathbf{0}}[\mathbf{P a}]$ & $\mathbf{T}^{\mathbf{0}}[\mathbf{K}]$ & $\rho\left[\mathbf{k g} / \mathbf{m}^{3}\right]$ & $\mathbf{x}_{\mathbf{N} 2}$ & $\mathbf{x}_{\mathbf{N}}$ \\
\hline \hline Case B [19] & 7.60 & $1.03352 \cdot 10^{7}$ & 5616 & 6.164 & 0.9883 & 0.0117 \\
\hline
\end{tabular}



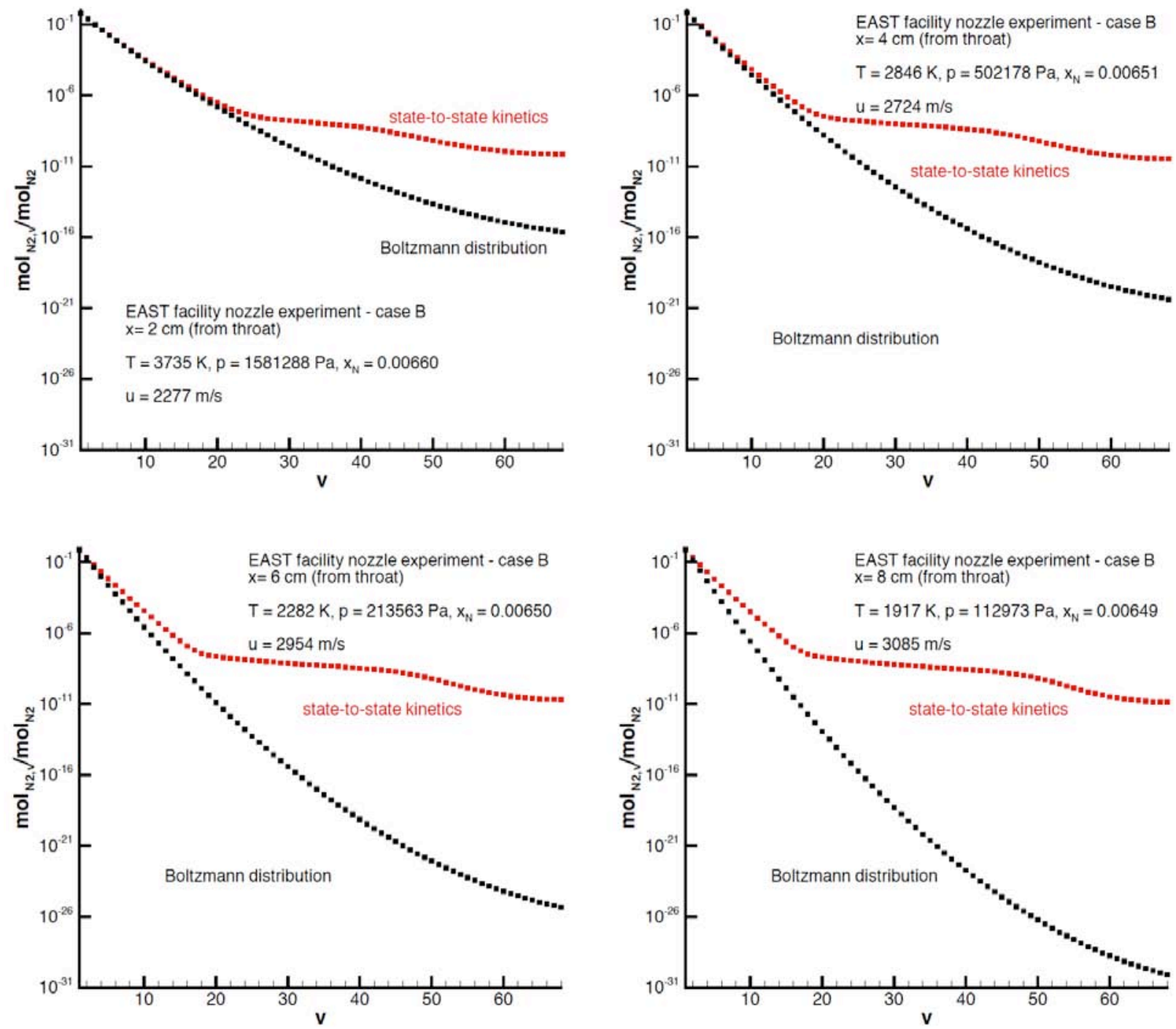

Fig. (14). Computed vibrational levels distributions at different positions along the EAST nozzle.

which may be due to the tails freezing mechanism. Note that the macroscopic model incorporates a chemistry-to-vibration mechanism that should enhance the recombination rate in the present experimental conditions. However, such a model is based on the hypothesis of a Boltzmann distribution for the vibrational energy levels and it does not account for deviation from it. Since the amount of dissociation in the present experiment is very small, further computations should be carried out considering stagnation conditions capable of producing a larger amount of atomic nitrogen. If, in those cases also, the recombination processes were more pronounced using the state-to-state model rather than the macroscopic model, this would be a proof that macroscopic models should incorporate some mechanism to account for the freezing of the population tails in strongly expanding flows.

With respect to the experimental data, which contain information about the vibrational temperature distribution along the nozzle, the present results are in very good agreement as far as the roto-traslational temperature is concerned, but they underestimate the value of the vibrational temperature. In Fig. (15) (right), we can see a ratio $\mathrm{T}^{\mathrm{v}}{ }_{\mathrm{N} 2} / \mathrm{T}^{\mathrm{o}}$ approximately equal to $0.51-0.52$, while experimental data measure values of about 0.58-0.6. Other models, both state-to-state and macroscopic [19], provide a definitely better agreement, though it must be put in evidence that at least part of them was tuned on this particular experiment.

\section{PRELIMINARY RESULTS OF TEST CASES WITHIN PHYS4ENTRY PROJECT}

In the framework of the Phys4Entry Project, funded by the European Community, several experimental test cases are being performed at the Von Karman Institute for Fluid Dynamics (VKI). The test cases will concern different gas mixtures corresponding to the atmosphere of different planets: Earth, Mars and Jupiter. Experiments concerning Earth and Mars will be carried out in the Plasmatron facility, while Jupiter atmosphere will be simulated in the VKI Minitorch. Several experimental data will be available, from standard calorimetric and pressure measurements to nonintrusive measurements with conventional and advanced spectroscopic diagnostics, with the aim of characterizing the supersonic expanding plasma jet in terms of internal levels 

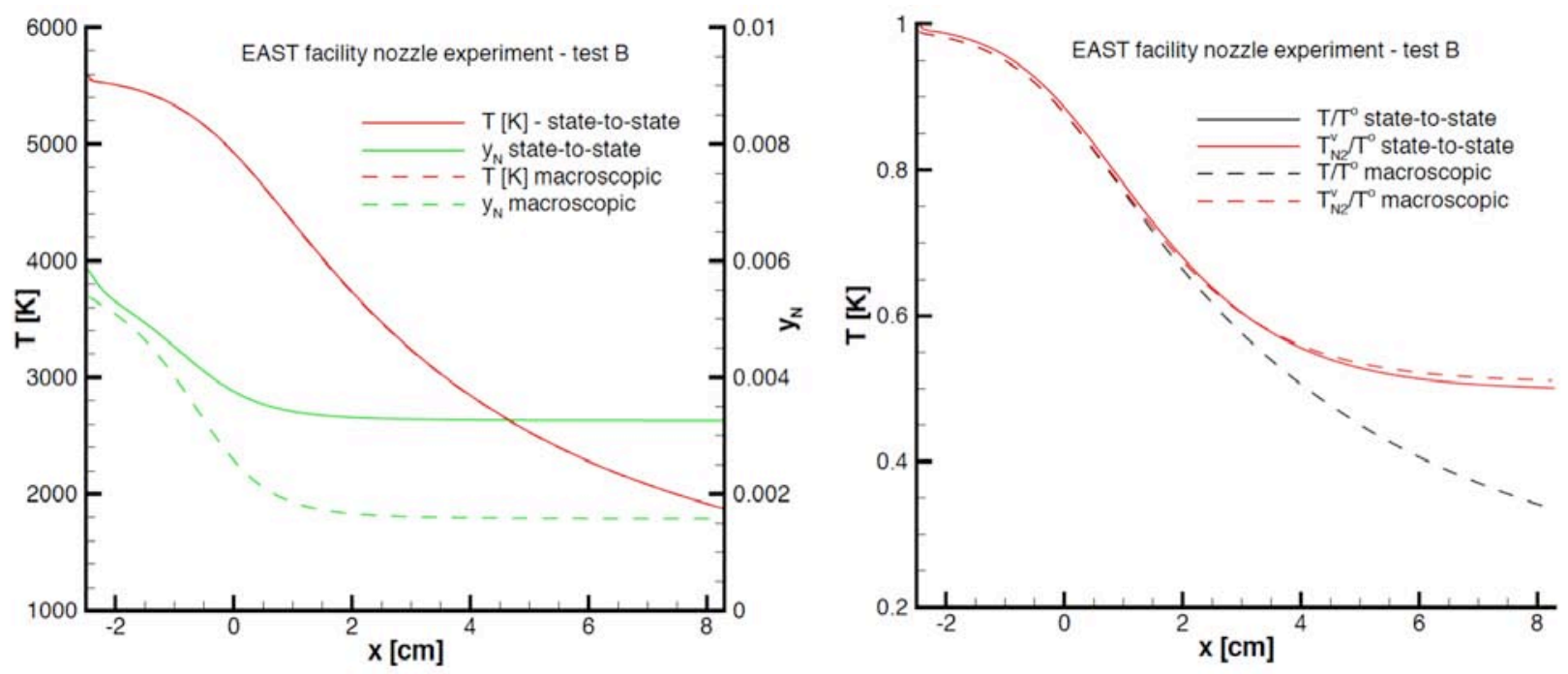

Fig. (15). Computed temperatures and chemical composition along the EAST nozzle.

Table 4. Plasma wind tunnel test conditions for nitrogen and air.

\begin{tabular}{|c|c|c|c|c|c|}
\hline Case & Power [kW] & Reservoir Pressure [mbar] & Chamber Pressure [mbar] & Mass Flow Rate [g/s] & Exit Nozzle Temperature [K] \\
\hline \hline Air case 1 & 490 & 120 & 6 & 4.5 & 10300 \\
\hline Air case 2 & 490 & 120 & 12 & 4.5 & 10300 \\
\hline $\mathrm{N}_{2}$ case & 500 & 97 & 10 & 4 & 8000 \\
\hline
\end{tabular}

populations, atom number densities, ionization degree and radiation signatures.

Preliminary experimental data, mainly concerning tests in nitrogen and in air, are shown in [20]. Hereinafter, some preliminary results of the CFD computations performed to rebuild such tests are described.

The nominal test conditions provided by VKI are reported in Table 4. The flow is assumed in chemical equilibrium at the nozzle entry.

The 2D axial-symmetric computational grid, generated by means of the grid generator ANSYS ICEM CFD ${ }^{\circledR}$, is shown in Fig. (16), with a detail of the sonic nozzle region.

In all the computations, thermo-chemical non-equilibrium is assumed and the chemical model due to Park [7] is adopted.

The nozzle wall is cooled $(300 \mathrm{~K})$ and therefore the test chamber walls have been modelled with fixed temperature condition.
The contour maps of the Mach number and pressure are shown in Fig. (17). The test chamber pressure is about 980 $\mathrm{Pa}$, therefore the experimental value is well reproduced. The sequence of oblique shocks that develops inside the test chamber and slows down the flow to exhaust conditions is clearly visible in the pressure distribution contours. The temperature at the nozzle exit section is $7700 \mathrm{~K}$, very close to the experimental value.

Roto-translational temperature, $\mathrm{N}_{2}$ vibrational temperature and mass fractions distributions along the nozzle axis (see Fig. 18) show that the flow is almost completely dissociated in the reservoir and that it undergoes a slight recombination during the expansion. In addition, it is in thermal equilibrium, as it is demonstrated by the fact that the dashed red line representing vibrational temperature is almost coincident with the solid line (roto-translational temperature).

A preliminary coupling between CFD and state-to-state computations is being performed according to the following
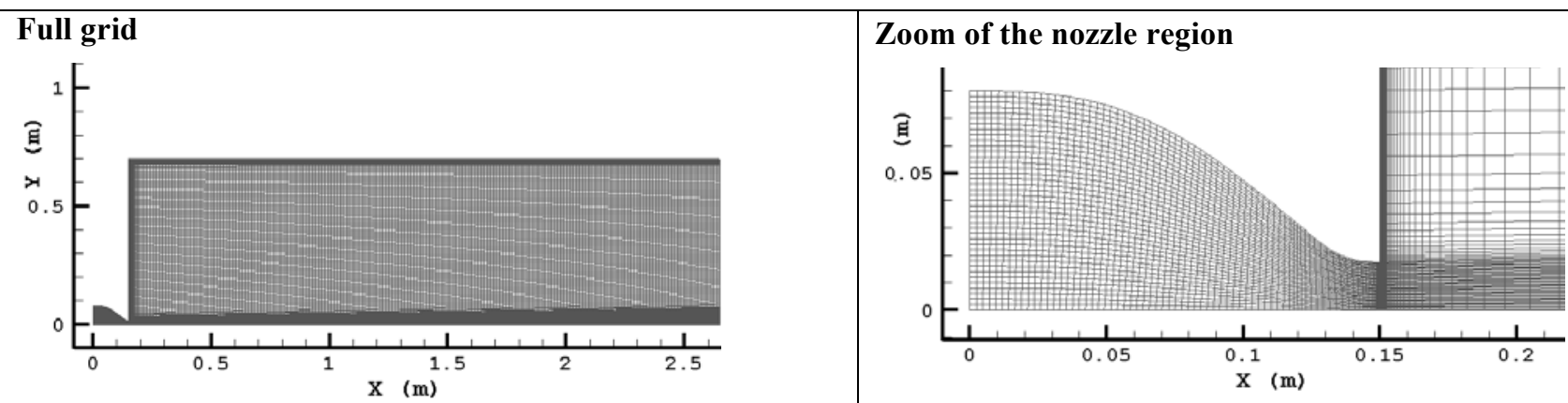

Fig. (16). Computational grid of the Plasmatron nozzle and chamber. 


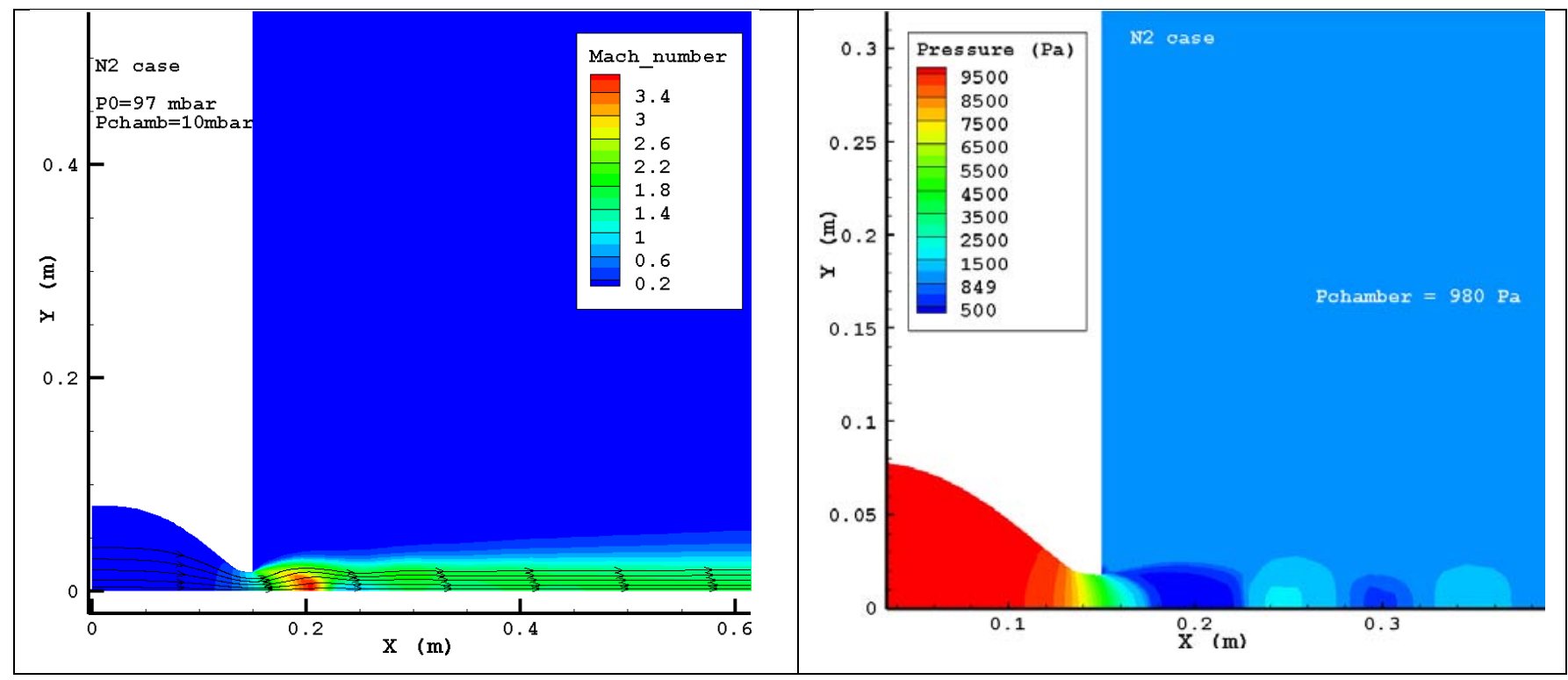

Fig. (17). Nitrogen case. Contour maps of Mach number (left) and pressure (right).

approach: CFD results will be integrated in time along a number of stream-traces, and provided as input conditions to a state-to-state 1D code available at CNR-IMIP. This will allow to compare the computed species concentrations, and in particular the electron number density, in simulations where state-to-state or macroscopic models are used. A further step will be the implementation of the state-to-state model directly in the CFD code, in order to perform 2D computations of the flow field.

Similar results were obtained for the test cases in air, where the effect of the chamber pressure (case 1, $\mathrm{P}$ _chamber $=600 \mathrm{~Pa}$, case $2, \mathrm{P}$ chamber $=1200 \mathrm{~Pa}$ ) can be analysed also. As soon as data for Mars and the Jupiter atmosphere will be available, they will be simulated as well.

It is worth underlining that the final goal of this activity is to validate the kinetic models developed in the framework of Phys4Entry project for Earth, Mars and Jupiter atmospheres, emphasizing the differences between the results obtained with macroscopic and state-to-state kinetic models.

\section{CONCLUSION}

In the first part of the present paper, the importance of using CFD simulations for the design of a hypersonic vehicle is stressed. It is emphasized how different approximation levels can be used, depending on the design phase and therefore on the required accuracy. Furthermore, after a description of the main parameters that are typically needed by the designer, it was underlined that these parameters must always be provided with a tolerance, and therefore with an estimated error bar, which depends on the accuracy of the used models and on the confidence that the CFD specialist has in the use of such models in relevant conditions.

Some examples of applications carried out by the authors in different projects are shown, aimed at the validation of physical, and in particular kinetic models in different conditions, for both external and internal flows. One of the most interesting results concerned the rebuilding of the flow field in the Scirocco nozzle [14], where the use of a novel model based on state-to-state approach led to a significant improvement in the prediction of the electron number density at the nozzle exit.

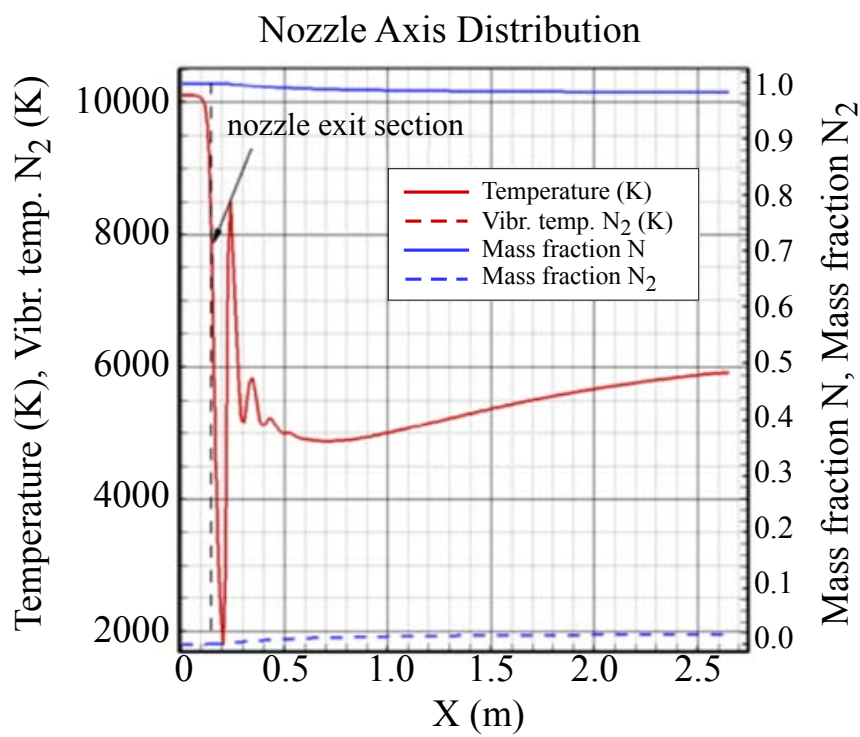

Fig. (18). Red lines: roto-translational and vibrational temperature (solid and dashed, respectively); blue lines: $\mathrm{N}$ and $\mathrm{N}_{2}$ mass fractions (solid and dashed, respectively).

Finally, some preliminary results of the activity carried out in the framework of Phys4entry project are shown, the goal being again the comparison between macroscopic models and state-to-state approach. In this work, a 1D stateto-state code was initially used, externally coupled with the CFD code using Park macroscopic model. The implementation of the state-to-state model directly in the CFD code is foreseen in the prosecution of the activity.

For the time being, nitrogen and air have been considered as working gas. As soon as the kinetic models for Mars and Jupiter atmospheres will be available from the Phys4entry project, these models will be also validated through 
comparison with additional experimental data measured at the VKI.

\section{NOMENCLATURE}

$$
\begin{array}{ll}
\mathrm{B} & =\text { Magnetic induction field } \\
C_{i} & =\text { Aerodynamic coefficient } \\
H_{0} & =\text { Total enthalpy } \\
n & =\text { Number density } \\
P_{0} & =\text { Total pressure } \\
T & =\text { Temperature } \\
x_{i} & =\text { Mole fraction of the } \mathrm{i} \text {-th species } \\
y_{i} & =\text { Mass fraction of the } \mathrm{i} \text {-th species }
\end{array}
$$

\section{Greek Letters}

$\alpha \quad=$ Ionization degree

$\rho \quad=$ Density

$\sigma \quad=$ Electrical conductivity

\section{Superscript}

$\begin{array}{ll}\text { Nom } & =\text { Nominal } \\ \text { Tol } & =\text { Tolerance } \\ \text { Var } & =\text { Variation }\end{array}$

Acronyms

$$
\begin{array}{ll}
\text { CFD }= & \text { Computational Fluid Dynamics } \\
C I R A= & \text { Italian Aerospace Research Center } \\
C L A E= & \text { Configuration analysis and Local } \\
& \text { Aerothermodynamic Effects (CIRA Project) } \\
C N R-I M I P= & \text { National Research Council - Institute of } \\
& \text { Inorganic Methodologies and Plasmas } \\
= & \text { Intermediate eXperimental Vehicle (ESA } \\
& \text { Project) } \\
= & \text { Magneto-Hydro-Dynamic } \\
M H D= & \text { Von Karman Institute } \\
V K I= & \text { Unmanned Space Vehicle (CIRA Program) }
\end{array}
$$

\section{CONFLICT OF INTEREST}

The authors confirm that this article content has no conflict of interest.

\section{ACKNOWLEDGEMENTS}

The Phys4Entry Project was funded by the European Community's Seventh Framework Program (FP7/2007-2013).

\section{REFERENCES}

[1] Druguet MC, Candler GV, Nompelis I. Effects of numerics on navier-stokes computations of hypersonic double-cone flows. AIAA J 2005; 43(3): 616-23.

Available from: http://arc.aiaa.org/doi/abs/10.2514/1.6190

[2] Shang JS, Surzhikov ST. Simulating nonequilibrium flow for ablative earth reentry. J Spacecr Rockets 2010; 47(5): 806-15. Available from: http://arc.aiaa.org/doi/abs/10.2514/1.49923
Tchuen G, Zeitoun DE. Effects of chemistry in nonequilibrium hypersonic flow around blunt bodies. J Thermophys Heat Transf 2009; 23: 433-42.

Available from: http://arc.aiaa.org/doi/abs/10.2514/1.4 2665

Rufolo GC, Roncioni P, Marini M, Votta R, Palazzo S. Experimental and numerical aerodynamic data integration and aerodatabase development for the PRORA-USV-FTB_1 reusable vehicle. AIAA Paper 2006-8031; 2006.

Available from: http://arc.aiaa.org/doi/abs/10.2514/6.2006-8031

Schettino A, Votta R, Roncioni P, et al., Eds. Aerodynamic and aerothermodynamic database of expert capsule. Conference Proceedings, West-East High Speed Flow Field Conference; 2007 Nov 19-22; Moscow 2007.

Pezzella G, Marini M, Rufolo G. Aerodynamic characterization of the ESA intermediate experimental vehicle. AIAA paper 20112232; 2006.

Available from: http://arc.aiaa.org/doi/abs/10.2514/6.2011-2232

Park C. Review of chemical-kinetic problems of future NASA missions, I: Earth entries. J Thermophys Heat Transf 1993; 7(3): 385-98. Available from: http://arc.aiaa.org/doi/abs/10.2514/3.431

[8] Kang SW, Jones WL, Dunn MG. Theoretical and measured electron-density distributions at high altitudes. AIAA J 1973; 11(2): 141-9.

Available from: http://arc.aiaa.org/doi/abs/10.2514/3.50446

[9] Schettino A, Battista F, Ranuzzi G, D’Ambrosio D, Eds Rebuilding of new experimental tests on a double cone at Mach 9. Conference Proceedings, 6th European Symposium on Aerothermodynamics for Space Vehicles; 2008 Nov 3-6; Versailles 2008.

[10] Nompelis I, Candler GV, Holden MS. Effect of vibrational nonequilibrium on hypersonic double-cone experiments. AIAA J. 2003; 41(11): 2162-9.

Available from: http://arc.aiaa.org/doi/abs/10.2514/2.6834

[11] Di Clemente M, Marini M, Di Benedetto S, Schettino A, Ranuzzi G, Eds. Numerical prediction of aerothermodynamic effects on a reentry vehicle body flap configuration. Conference Proceedings, Space Transportation Symposium 2006; IAC-06-D2.6.08.

[12] Di Clemente M, Sellitto C, Vigliotti A, Martucci A, Marini M. Shock wave boundary layer interaction measurement assembly on the expert capsule. AIAA Paper 2009-7217; 2009. Available from: http://arc.aiaa.org/doi/abs/10.2514/6.2009-7217

[13] Cristofolini A, Borghi CA, Neretti G, et al. Experimental investigations on the magneto-hydro-dynamic interaction around a blunt body in a hypersonic unseeded air flow. J Appl Phys 2012; 112(9): 93304. Available from: http://scitation.aip.org/content/aip/ journal/jap/112/9/10.1063/1.4764105

[14] Cristofolini A, Borghi CA, Schettino A, Battista F. Numerical rebuilding of MHD tests in an unseeded mach 10 air flow around a blunt body. AIAA paper 2012-2733; 2012. Available from: http://arc.aiaa.org/doi/abs/10.2514/6.2012-2733

[15] Trifoni E, Purpura C, Martucci A, et al., Eds. MHD experiment at CIRA GHIBLI plasma wind tunnel. Conference Proceedings, 7th Aerothermodynamics Symposium; 2011 May 9-12; Bruges (Belgium) 2011.

[16] Colonna G, D'Ambrosio D, Capitelli M. Consistent comparison of macroscopic and state-to-state kinetics in hypersonic flows. AIAA Paper 2007-3906; 2007.

Available from: http://arc.aiaa.org/doi/abs/10.2514/6.2007-3906

[17] Sharma SP, Ruffin SM, Gillespie WD, Meyer SA. Vibrational relaxation measurements in an expanding flow using spontaneous Raman scattering. J Thermophys Heat Transf 1993; 7(4): 697-703. Available from: $\mathrm{http}: / /$ arc.aiaa.org/doi/abs/10.2514/3.479

[18] Gillespie WD, Bershader D, Sharma SP, Ruffin SM. Raman scattering measurements of vibrational and rotational distributions in expanding nitrogen. AIAA Paper 1993-0274; 1993. Available from: http://arc.aiaa.org/doi/abs/10.2514/6.1993-274

[19] Ruffin SM. Prediction of vibrational relaxation in hypersonic expanding flows part 2: Results. J Thermophys Heat Transf 1995; 9(3): 438-45.

Available from: http://arc.aiaa.org/doi/abs/10.2514/3.56309

[20] Babou Y, Lequang D, Chazot O, et al. Thermodynamic characterization of high-speed and high-enthalpy plasma flows. Open Plasma Phys J 2013; in press. 
[21] Millikan RC, White DR. Systematic of vibrational relaxation. J Chem Phys. 1963; 39(12): 3209-13. Available from: http://scitati on.aip.org/content/aip/journal/jcp/39/12/10.1063/1.1734182

[22] Yun KS, Mason EA. Collision integrals for the transport properties of dissociating air at high temperatures. Phys Fluids 1962; 5(4): 380-6. Available from: http://scitation.aip.org/content/aip/journal/pof1/5/4/10.1063/1.1706629

Borrelli S, Pandolfi M, Eds. An upwind formulation for the numerical prediction of non equilibrium hypersonic flows.

Conference Proceedings, 12th International Conference on Numerical Methods in Fluid Dynamics; Oxford (UK) 1990.

(C) Schettino and D'Ambrosio; Licensee Bentham Open.

This is an open access article licensed under the terms of the Creative Commons Attribution Non-Commercial License (http://creativecommons.org/licenses/by-nc/3.0/) which permits unrestricted, non-commercial use, distribution and reproduction in any medium, provided the work is properly cited. 